\title{
Analysis of wet-steam microturbine self-regulation characteristics
}

\author{
Nikolai N. Efimov ${ }^{1}$, Sergei V. Skubienko1, Vadim V. Kopitsa ${ }^{2, *}$, Dmitry V. Stepovoy ${ }^{3}$, \\ Alexander D. Ovechkin ${ }^{2}$ and Vasiliy N. Baltyan ${ }^{1}$ \\ ${ }^{1}$ South-Russian State Polytechnic University (Novocherkassk Polytechnic Institute) M.I. Platova, \\ 346400 Novocherkassk, Russia \\ ${ }^{2}$ Limited Liability Company Innovation and Technological Center "Donenergomash", 344022 \\ Rostov-on-Don, Russia \\ ${ }^{3}$ Azov - Black Sea Engineering Institute - branch of FSBEI HE «Don State Agrarian University», \\ 347740 Zernograd, Russia
}

\begin{abstract}
The paper analyzes the characteristics of a wet-steam microturbine self-regulation with a constant and variable consumption of a wet steam, depending on the rotor speed of the turbine. The characteristics of self-regulation are the electric power, the consumption load and the torque generated on the microturbine blades. The dependence of electric power on the rotation speed for a wet-steam microturbine with a power of $5 \mathrm{~kW}$ is constructed.
\end{abstract}

\section{Introduction}

Steam turbines have been used for more than 100 years as drives to electric generators in the electricity production. Their installed capacity grew along with the need for more and more energy production for consumers $[1,2,3]$. The strategy for the energy development in Russia and further assumes the use of steam turbines at thermal and nuclear power plants [4]. The rotor speed of steam and gas turbines of high power was adjusted depending on the alternating current frequency of $50 \mathrm{~Hz}$. Thus, most steam turbines operate at a rotational speed of $3000 \mathrm{rpm}$. In some cases, a frequency of $1500 \mathrm{rpm}$ is also used, i.e. the value is a multiple of $3000 \mathrm{rpm}$. Change this rotation speed in the operating modes of high-power turbines in thermal and nuclear power plants (TPPs, NPPs) is not allowed, so as not to violate the alternating currentfrequency in electrical networks. In this regard, steam turbines are equipped with a sophisticated automatic control system to maintain these revolutions $[5,6]$. As a rule, this is a hydrodynamic control with a complex of speed sensors, spool signal amplifiers, servomotors for driving actuators acting on regulating (or throttling) valves. In addition, safety devices are installed on the turbines, preventing unnecessary increase in the rotation speed relative to the rated speed. Recently, microenergy plants (gas, gas piston, wet steam microturbines) are becoming increasingly popular [7, 8]. It is not advisable to provide a complex system for regulating the rotational speed of the microturbine rotor. Therefore, another control principle is used for this technique, which consists in the fact

\footnotetext{
* Corresponding author: vadimnpi@mail.ru
} 
that the rotational speed of the microturbine rotor can change, and the alternating currentfrequency is maintained within predetermined limits by the electronic system of converters and current regulators [9].

\section{Design features of steam turbines}

The structural scheme of a steam microturbine at a vapor pressure of not more than $1.5 \mathrm{MPa}$ and a temperature of up to $200^{\circ} \mathrm{C}$ can be performed in the following variants:

1) single-stage axial microturbine of horizontal execution (see Fig. 1, a);

2) single-stage centripetal single-flow microturbine of horizontal design (Fig. 1, b);

3) single-stage centripetal double-flow microturbine of horizontal design (Fig. 1, c);

4) single-stage centripetal single-flow microturbine of vertical design (Fig. 1, g).

When analyzing the microturbine circuits under consideration, the initial characteristics are assumed to be the same for a correct comparison of these options: electric power $30-50 \mathrm{~kW}$; wet vapor pressure 0.6-1.0 $\mathrm{MPa}$; the temperature is $160-180^{\circ} \mathrm{C}$.

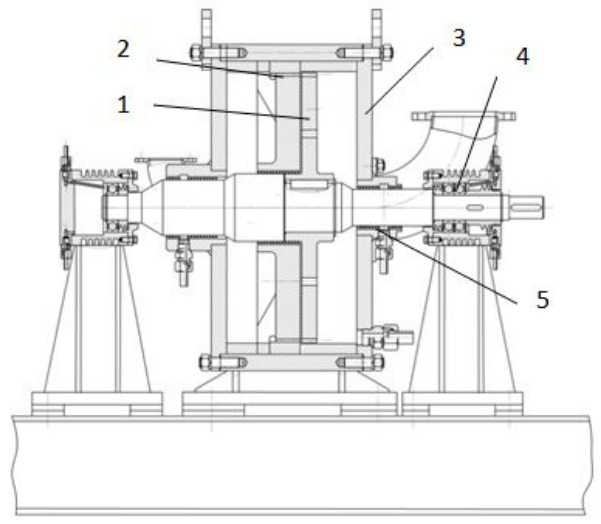

a)

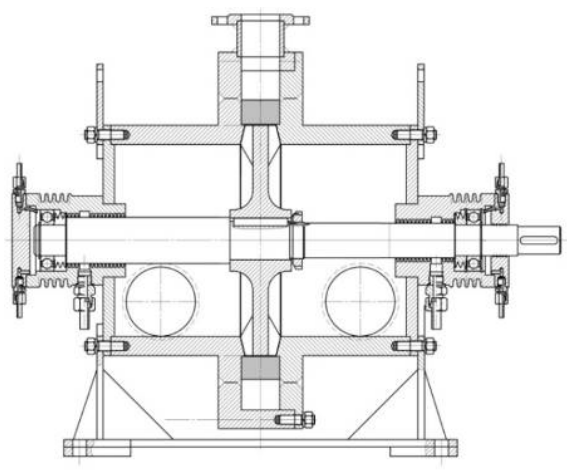

c)

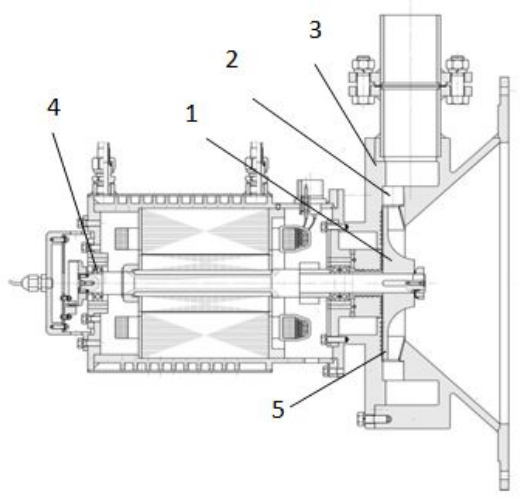

b)

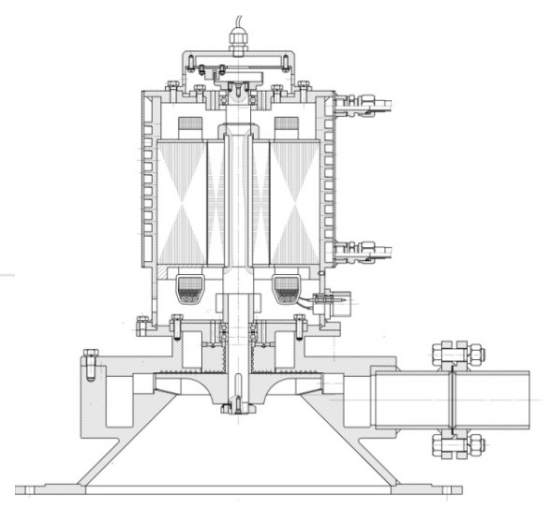

d)

Fig. 1. Constructive schemes of microturbines with a capacity of 30-50 MW: 1 - the impeller; 2 - nozzle apparatus; 3 - housing; 4 - bearings ( 2 pcs); 5 - seals.

With a heat drop of $300 \mathrm{~kJ} / \mathrm{kg}$ or more, in a single-stage microturbine the rate of vapor outflow from the nozzle apparatus will always be supersonic. Forin order to create subsonic 
vapor velocities, a microturbine must be performed at least three-stepwise. Hence, a dilemma appears in the choice of the flow section design- a single-stage microturbine and supersonic steam velocities, or subsonic speeds, but a three-stage flow section. In the first version of the supersonic turbine design, it is required to qualitatively perform the profiling of the flow section.

When the microturbine is multistage, the shaft length is also increased because when the steam is supplied to the stage in part, it is necessary to perform expanded chamber volumes before the second and subsequent stages. Thus, with increased rotationspeedsof the turbine rotor, the shaft becomes flexible, which leads to the appearance of critical resonance oscillations of the shaft when the turbine leaves the nominal rotational speed.

The heat transfer in the bulk of the metal and the working medium is of great importance for the wet-steam turbines operation. The highest temperature of the coolant is observed in the chamber when entering the nozzle apparatus. The lowest temperature does not leave the working grate. The heat from the heat carrier (wet vapor) is transferred to the metal part of the body and the turbine rotor and influences the thermal expansion of these elements in the microturbine. In order that these expansions do not have a harmful effect, the thermal fields must, on the one hand, be symmetrically identical around the rotation axis and not create high temperatures in the metal of the bearing supports.

\section{Analysis of self-regulation characteristics of microturbines with constant steam parameters at the input}

In this paper, the steam microturbine behavior is analyzed with a change in the load on the rotor at constant parameters before the nozzle apparatus of the first stage and at the turbine outlet. The computational analysis was carried out taking into account [10]. For the analysis, let us consider the main characteristics of the turbine:

1) the torque dependence on the turbine blades on the number of revolutions $M_{\mathrm{T}}=f(n)$;

2) the power dependence on the turbine blades on the speed $N_{m}=f(n)$ as an engine in the absence of an automatic control system, i.e., the self-regulation characteristics of the turbine under the condition that the steam flow rate is constant through the turbine $(G=$ const $)$ and the pressure and vapor pressure before the turbine ( $p_{0}=$ const, $t_{0}=$ const) and steam pressure after the turbine $\left(p_{k}=\right.$ const).

We determine the moment, Hm, and power, $\mathrm{W}$, depending on the rotation speed $\mathrm{M}_{\mathrm{T}}=f(n)$ and $N_{m}=f(n)$ for the example of one turbine stage in accordance with Euler formulas for turbomachines (see Fig. 1) [2, 3].

Fig. 2 shows the axial turbine stepper blade grids and speed triangles for the three operating modes: a) $n=0$; b) $n=$ mean; c) $n=n_{\max }$.

$$
\begin{gathered}
M_{m}=P_{u} \cdot r=G\left(c_{1 \mathrm{u}}-c_{2 \mathrm{u}}\right) \cdot r, \\
N_{m}=M_{m} \cdot \omega=G\left(c_{1 \mathrm{u}}-c_{2 \mathrm{u}}\right) \cdot r \cdot 2 \pi \cdot n,
\end{gathered}
$$

where $P_{u}=G\left(c_{1 \mathrm{u}}-c_{2 \mathrm{u}}\right)$ is the circumferential force on the turbine's turbine blades, $\mathrm{H}$; $r$ - is the average radius of the axial turbine stage, $\mathrm{m} ; c_{1 \mathrm{u}}$ - the circumferential component of the absolute steam velocity at the entrance to the working grid of the stage, $\mathrm{m} / \mathrm{s} ; c_{2 \mathrm{u}}-$ is the circumferential component of the absolute steam velocity at the exit from the working grid of the stage, $\mathrm{m} / \mathrm{s} ; \omega-$ is the angular velocity of the turbine rotor rotation, $1 / \mathrm{s}$.

The variable value is the circumferential velocity $u, m / s$, or the number of revolutions $n, 1 / s: u=2 \pi \cdot r \cdot n$.

$$
\begin{gathered}
\text { Replacing }\left(c_{1 \mathrm{u}}-c_{2 \mathrm{u}}\right)=\left[\left(c_{1 \mathrm{u}}-c_{2 \mathrm{u}}\right)_{\max }-u\right],(\text { see Fig. 1), we get: } \\
M_{t}=G \cdot r \cdot\left[\left(c_{1 \mathrm{u}}-c_{2 \mathrm{u}}\right)_{\max }-u\right]=G \cdot r \cdot\left[\left(c_{1 \mathrm{u}}-c_{2 \mathrm{u}}\right)_{\max }-2 \pi \cdot r \cdot n\right]=A-B \cdot n,
\end{gathered}
$$


where $A=G \cdot r \cdot\left(c_{1 \mathrm{u}}-c_{2 \mathrm{u}}\right)_{\max }=$ Const, $B=G \cdot r \cdot 2 \pi \cdot r=$ Const.

Equation (1) is the equation of a straight line in coordinates $M t-n$ (see Fig. 3).

$$
\begin{gathered}
M_{m}=M_{m} \max =G \cdot r \cdot\left(c_{1 \mathrm{u}}-c_{2 \mathrm{u}}\right)_{\max } \text { for } n=0 . \\
M_{m}=0 \text { for } u_{\max }=\left(c_{1 \mathrm{u}}-c_{2 \mathrm{u}}\right)_{\max } \text { or } n_{\max }=\left(c_{1 \mathrm{u}}-c_{2 \mathrm{u}}\right)_{\max } / 2 \pi \cdot r . \\
M_{m}=M_{\mathrm{T} \max }=G \cdot r \cdot\left(c_{1 \mathrm{u}}-c_{2 \mathrm{u}}\right)_{\max } \text { for } n=0 . \\
M_{m}=0 \text { for } u_{\max }=\left(c_{1 \mathrm{u}}-c_{2 \mathrm{u}}\right)_{\max } \text { or } n_{\max }=\left(c_{1 \mathrm{u}}-c_{2 \mathrm{u}}\right) \max / 2 \pi \cdot r .
\end{gathered}
$$

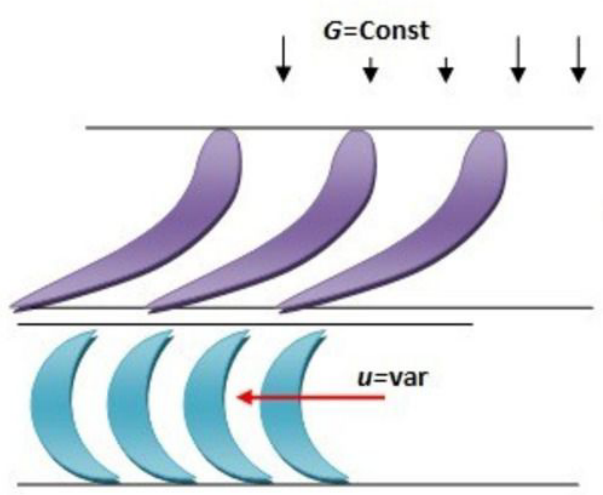

a)

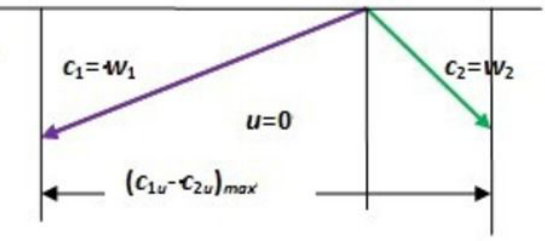

6)

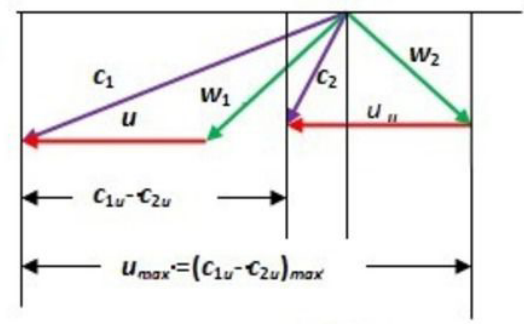

в)

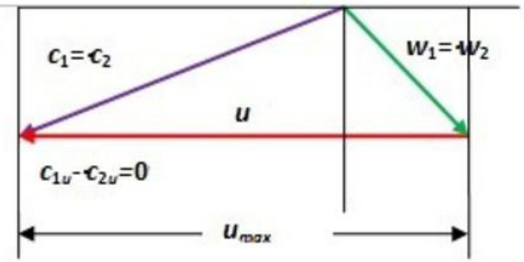

Fig. 2. Turbine stage blades and speed triangles.

The power equation on the turbine blades from the speed $N_{m}=f(n)$ takes the form:

$$
\begin{gathered}
N_{m}=M_{m} \cdot \omega=G \cdot r \cdot\left[\left(c_{1 \mathrm{u}}-c_{2 \mathrm{u}}\right)_{\max }-u\right] \cdot 2 \pi \cdot n= \\
=G \cdot r \cdot\left[\left(c_{1 \mathrm{u}}-c_{2 \mathrm{u}}\right)_{\max }-2 \pi \cdot r \cdot n\right] \cdot 2 \pi \cdot n=A 1 \cdot n-B 1 \cdot n^{2},
\end{gathered}
$$

where $A_{1}=G \cdot r \cdot\left(c_{1 \mathrm{u}}-c_{2 \mathrm{u}}\right)_{\max } \cdot 2 \pi=$ const, $B_{1}=G \cdot r \cdot 2 \pi \cdot r=$ const.

Equation (2) - is the parabola equation in the coordinates $N_{m}-n$ (see Figure 2).

The turbine blade power is $N_{m}=0$ for $n=0$ and for $n_{\max }=\left(c_{1 \mathrm{u}}-c_{2 \mathrm{u}}\right)_{\max } / 2 \pi \cdot r$. For a multi-stage turbine, the power on the blades of $N_{m}$ and the torque at the blades of the turbine $\mathrm{Mm}$ are determined by summing $\Sigma N_{m}$ and $\Sigma M_{m}$ of all stages. The forms of graphs for a multi-stage turbine and one stage will be similar.

Let us consider some properties of a turbine as a control object.

Fig. 3 shows the change lines in the torque $M_{m}$ developed by the steam expanding in the turbine $\left(M_{m 0}=f(n)\right)$, the power of the turbine $\left(N_{m 0}=f(n)\right)$ at a constant flow rate of steam (which corresponds to a certainopening of control valves) and braking resistance load $\left(N_{\text {nagr } 0}=f(n)\right)$ on the consumer shaft of the mechanical power in the turbomachine (pump, compressor). 
The steady-state operating mode, at which $N_{m 0}=N_{\text {nagro }}$, corresponds to the intersection of the characteristics at point $\mathrm{A}$ at a rotation frequency $\mathrm{n}_{0}$.

If the load of the consumer in mechanical power changes, for example, with a decrease in the waterflow passing through the pump, the pump characteristic will shift to the position determined by the curve $N_{\text {nagrl }}$. If the steam parameters and the position of the turbine control valves remain unchanged, the new stationary mode the turbine and pump operation, as a single unit, will be reached at point $B$. Thus, the turbine and pump can move from one stable operating mode to another without any external. The impact on them is due solely to the self-regulation process.

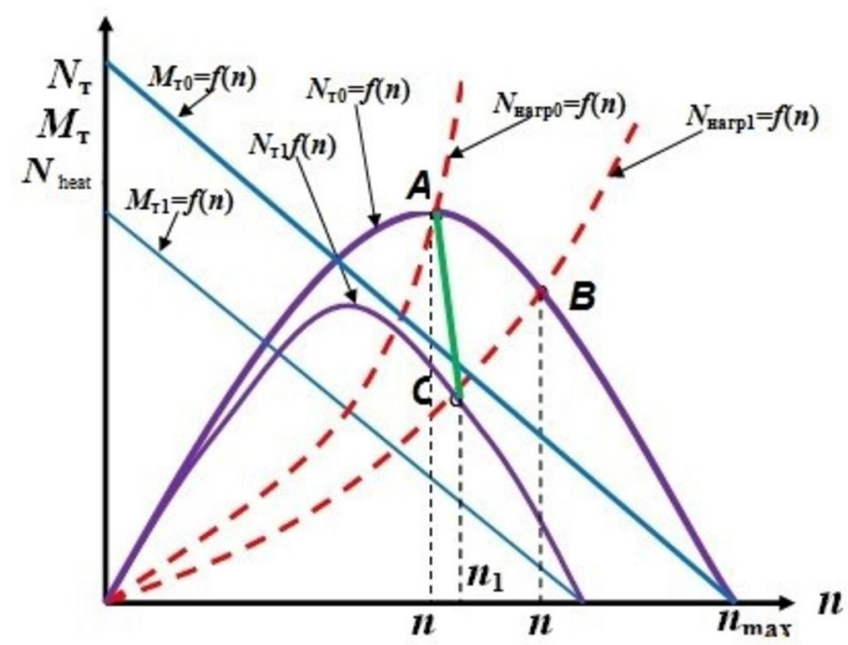

Fig. 3. Turbine self-regulation characteristics and load characteristics.

In the absence of automatic regulation and $G_{0}=$ const, all possible steady-state turbine operation modes correspond to the line $N_{m 0}=f(n)$, which in this case is its static characteristic. It should be noted, however, that changes in the rotational speed $\left(n_{1}>>n_{0}\right)$ that occur during the self-regulation process can be unacceptably high with respect to the turbinereliability and pump operation.

In the absence of automatic regulation and changing the steam flow from 0 to $G_{0}(G=$ var), all possible steady-state turbine operation modes correspond to the area under the line $N_{m 0}=f(n)$, which shows the turbinepossibilities as an engine.

Therefore, it becomes necessary to control the turbine in such a way that the rotorspeed remains constant or varies within given narrow limits, which is why a complex control system is applied to powerful power installations.

\section{Analysis of the microturbines self-regulation characteristics with varying parameters of steam at the inlet}

In the steady-state operating mode, the torque on the turbine shaft is equal to the rotation moment of the load: $M_{m}=M_{\text {nagr }}$.

If the steady state of operation is disturbed, the angular acceleration of the turbine shaft rotation will appear:

$$
M_{t}=M_{\text {nagr }}+J \cdot d \omega / d \tau
$$

where $J-$ is the total moment of the shafting inertia, $\mathrm{kg} \cdot \mathrm{m}^{2} ; \mathrm{d} \omega / \mathrm{d} \tau-$ angular acceleration of shafting, $\mathrm{s}^{-2}$. 
Restoration of steady-state conditions is possible only with the help of a turbine automatic control system when the turbine moment $M_{\mathrm{T}}$ changes. When changing the pump load and shifting the pumpcharacteristics, the turbine characteristic (figure 3, curve $N_{t 1} f(n)$ ) should also be displaced by means of the turbine automatic control system, which will reduce the steam flow to the turbine. A new equilibrium operation mode will be achieved in volume $\mathrm{C}$ at a rotation frequency $n_{1}$, only slightly exceeding $n_{0}$.

All possible operating modes of the turbine unit with a joint change in the turbine and the pump characteristics are determined by the $\mathrm{AC}$ line, which is a controlledturbine unit static characteristic.

Allowing some small deviation of the speed from the set value, you can use it as a command pulse for the turbine automatic control. On this fundamental principle in control over the deviation of $\mathrm{n}$, all turbine speed control systems are constructed without exception. To increase the speed in them, additional pulses can be used for the angular acceleration $\mathrm{d} \omega / \mathrm{d} \tau$ or for the load (disturbance).

\section{Microturbine control characteristics taking into account additional losses in the microturbine}

The turbine self-regulation characteristics are shown in Fig. 3 (power equation on the turbine blades from the speed $N_{\mathrm{T}}=f(n)$ ) do not take into account additional losses in the turbine. The electric power of the turbine driving the electric generator or the pump is less than the power on the turbine blades by the power amount of additional losses in the turbine.

Fig. 4 shows the calculated dependencies of electrical power in a single-stage centripetal turbine, taking into account additional losses from the rotational speed with a change in steam flow by changing the control valve opening degree. The microturbine nominal parameters: power $N_{\text {nom }}=5 \mathrm{~kW}$; the consumption of wet steam is $0.03 \mathrm{~kg} / \mathrm{s}$; the pressure of wet steam before the turbine is $0.6 \mathrm{MPa}$; temperature of wet steam $160{ }^{\circ} \mathrm{C}$; the graphs shapes $N_{e}=f(n)$ of the centripetal turbine are similar to the power dependences on the axial turbine blades $N_{\mathrm{T}}=f(n)$.

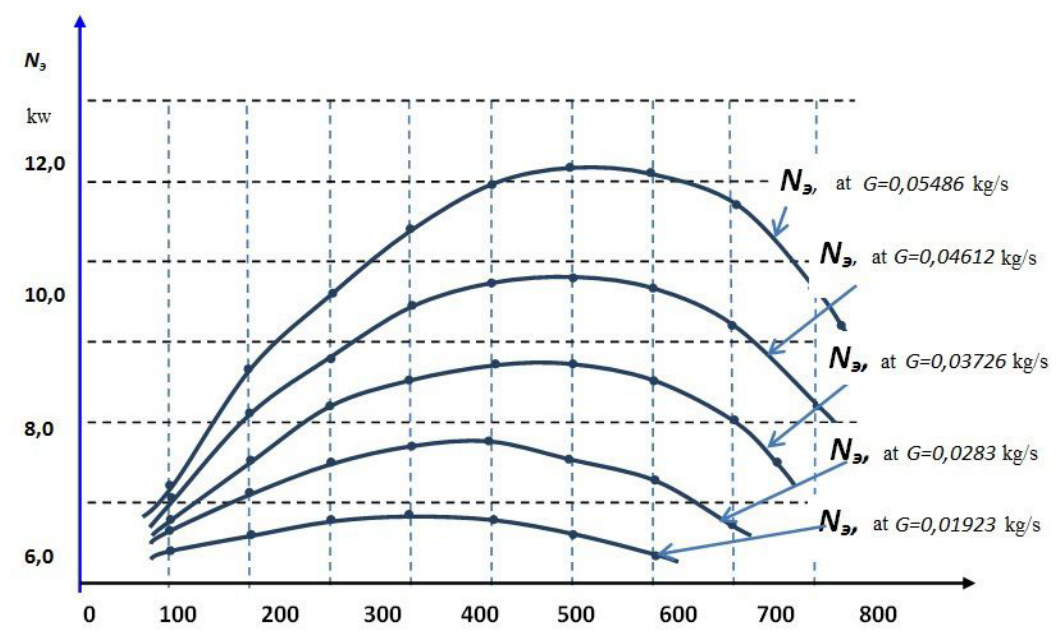

Fig. 4. The electric power dependence graphs of the turbine $\mathrm{N}_{\text {nom }}=5 \mathrm{~kW}$ on the rotation speed when the steam flow rate is changed 


\section{Results}

Based on the analysis, the microturbine self-regulation characteristics are defined:

- the power dependencies developed in the microturbines stages and consumption loads are constructed, which, when combined on a common graph, determine the rotoroperating speed;

- when the consumption load changes with a steam constant flow entering the turbine, the rotor speed of the turbine changes;

- the proportional dependence of the torque on the rotational speed blades of the microturbine rotor is presented;

- the dependence of the electric power a microturbine with a power of $5 \mathrm{~kW}$ is determined taking into account additional losses in the flowing part from the rotor rotation speed at a wet steam flow rate from $0.019 \mathrm{~kg} / \mathrm{s}$ to $0.055 \mathrm{k} / \mathrm{s}$.

The article was published with financial support by the Ministry of Education and Science of the Russian Federation within the framework of the Federal Target Program "Research and development in the priority directions of the scientific-technological complex of Russia for 2014-2020" (No. 14.577.21.0260 Agreement on "Development of an autonomous mobile micro-energy complex functioning on the basis of technologies of processing of the industrial, municipal and agricultural wastes with power supply with the trigeneration mode". The unique identifier of the applied scientific research and experimental developments (of the project) is RFMEFI57717X0260).

\section{References}

1. A. F. Dyakova, Power engineering in Russia. History and development prospects (JSC Informenergo, Moscow, 1997)

2. A. G. Kostyuk, V. V. Frolov, A. E. Bulkin, A. D. Trukhny, Thermal and nuclear power plants turbines (Publishing House MEI, Moscow, 2001)

3. A. N. Smolensky, Steam and gas turbines (Mechanical Engineering, Moscow, 1977)

4. Energy strategy of Russia for the period until 2020 (GU IES of the Ministry of Energy of Russia, Moscow, 2001)

5. G. P. Pletnev, Automated control systems for thermal power plants (Publishing House MEI, Moscow, 1995)

6. V. Ya. Rotach, Theory of heat and power processes automatic control (Energoattomizdat, Moscow, 1985)

7. N. N. Efimov, OS Popel, V. N. Baltián, Izv. universities. North-Caucasus.region. Techn.science, 1, 60 (2015)

8. N. N. Efimov, V. I. Parshukov and et al. Izv. universities. North-Caucasus.region. Techn.science, 1, 51 (2013)

9. V. I. Simonov, V. I. Parshukov et al. Alternative Energy and Ecology, 14 (154), 94 (2014)

10. N. N. Efimov, I. Ya. Shestachenko, Materials VIII International. sci. Conf., Novocherkassk, South-Russian Federation.state. tech. un-t (NPI), 41 (2012) 